\title{
Reconsidering prenatal screening: an empirical- ethical approach to understand moral dilemmas as a question of personal preferences
}

\author{
E García, ${ }^{1,2}$ D R M Timmermans, ${ }^{1}$ E van Leeuwen ${ }^{2}$
}

${ }^{1}$ EMGO Institute, Free University Medical Center (VUMC), The Netherlands; ${ }^{2}$ Department of Ethics, Philosophy and History of Medicine, University Medical Center, St Radboud, Nijmegen, The Netherlands

\section{Correspondence to:}

Dr E García, Department of Ethics, Philosophy and History of Medicine, University Medical Center St Radboud, Nijmegen, P. 0. Box 9191, $6500 \mathrm{HB}$ Nijmegen, The Netherlands; e.garciagonzalez@iq.umcn.n

Received 31 July 2008 Revised 26 February 2009 Accepted 15 April 2009

\section{ABSTRACT}

In contrast to most Western countries, routine offer of prenatal screening is considered problematic in the Netherlands. The main argument against offering it to every pregnant woman is that women would be brought into a moral dilemma when deciding whether to use screening or not. This paper explores whether the active offer of a prenatal screening test indeed confronts women with a moral dilemma. A qualitative study was developed, based on a randomised controlled trial that aimed to assess the decision-making process of women when confronted with a test offer. A sample of 59 women was interviewed about the different factors balanced in decision-making. Participants felt themselves caught between a need for knowledge and their unwillingness to take on responsibility. Conflict was reported between wishes, preferences and ethical views regarding parenthood; however, women did not seem to be caught in a choice between two or more ethical principles.

Participants balanced the interests of the family against that of the fetus in line with their values and their personal circumstances. Therefore, we conclude that they are not so much faced with an ethical dilemma as conflicting interests. We propose that caregivers should provide the opportunity for the woman to discuss her wishes and doubts to facilitate her decision. This approach would help women to assess the meaning of testing within their parental duties towards their unborn child and their current offspring.

Although prenatal screening for Down syndrome and neural-tube defects has become routine prenatal care in most western countries, health policy in the Netherlands has been reluctant to offer screening to all pregnant women. At the time this study was performed (2002-2004) only women in high-risk categories, of advanced maternal age (from 36 years old) or with medical indications, were offered invasive testing. Active offering of screening tests to women with a low risk was forbidden; the test could be performed only on request.

One of the main reasons for the Dutch government to limit prenatal screening is that an unsolicited offer would bring women into a moral dilemma when considering whether or not to have the test performed. ${ }^{2}$ This dilemma can be sketched as follows: because there is no therapy available, women receiving abnormal results would be forced to make a choice between two equally binding and mutually exclusive ethical principles, namely the moral duties of "respecting the life of the unborn" and "avoidance of suffering". These two principles support two incompatible options: bringing the pregnancy to term (implying direct responsibility for the suffering of a disabled child), or opting for termination and therefore violating the right to life of the fetus. The impossibility of foreseeing either the degree of suffering or the consequences of a particular disability makes it difficult to determine which is the best choice from a moral perspective. ${ }^{3-6}$

For their part, proponents of routine offering of prenatal screening claim the right of the parents to be informed about all existing test to make autonomous and well-considered decisions. ${ }^{7}$

This discussion in the Netherlands indicates a need for more research about the issues involved in routine offering of prenatal screening. Many studies have been performed on the decisionmaking involved in prenatal testing. ${ }^{8-16}$ From these studies, it seems that women experience difficulty in determining what is the best choice. ${ }^{17-20}$ In this paper we analyse whether this difficulty should be considered as an ethical dilemma. Although the Dutch policy changed in January 2007, so that women with low risk have to be informed about the possibility of screening, the study we performed was carried out in 2002-2004, and thus we made use of an unique opportunity to study the effect of an active test offer on women's decisionmaking in a context where prenatal screening was not routine, but rather part of a randomised controlled trial (RCT). The RCT consisted of three different groups: (1) one receiving the offering of a maternal serum test (MST), (2) one receiving the offering of a nuchal translucency measurement (NTM) and (3) a control group. ${ }^{12} 21$

A qualitative study was developed on the basis of the RCT to obtain more insight into the effect of ethical beliefs on decision making. This paper reflects the results of the qualitative study. We explored the effect of a test offer on the decisional process and the various factors women balanced when deciding whether or not to accept the offer. ${ }^{22} 23$

\section{METHODS}

A special permit for explicitly offering prenatal screening was granted by the Minister of Health and by the Medical Ethics Committee of the VU University Medical Centre.

\section{Participants}

Participants of the RCT who were in the process of deciding about the test were randomly selected and asked by phone to participate in an interview. Participants were randomly selected and asked to 
make an appointment within a week after the test was offered and before the test would eventually performed. In total 59 women agreed to be interviewed (26 from the MST group and 33 from the NTM group). As we were investigating here only the effect of the test offer, we did not include participants from the control group. Participants of the control group would have needed to be fully informed about the possibility of testing, thereby breaking the protocol of the RCT.

\section{Interviews}

Semi-structured interviews were chosen to make it possible for the participants to explain their own experience about the test offer and to allow a deeper insight into the women's motivations for their choice. The interviews lasted approximately 1 hour, and were conducted at the participant's home (by EG and other professional interviewers with the VUMC). With the participant's permission, all interviews were recorded and transcribed. To guarantee anonymity, each woman was allocated a number code.

Interviews started with open-ended questions about the woman's reasons for accepting of declining the test. To explore the various factors involved in the decision we included questions about the woman's reasons for her decision and her feelings regarding her choice. Subsequently, we extended the discussion to the participants' ethical views about issues relating to prenatal testing, ie, parental duties toward the unborn and current offspring; the worth of a disabled life, the acceptability of controlling the offspring's characteristics, the status of the fetus, and the permissibility of termination in general and for Down syndrome in particular. ${ }^{24-27}$ The interview questions were assessed for their intelligibility after performing the five first interviews, and it was considered that no adaptation was needed.

\section{Data analysis}

The womrn's views regarding testing and thier reasons for her decision were analysed with Nudist-Vivo (N-Vivo) software V.2.0 (OSR Software, Durham, UK). Segments of the interview were coded, and codes were then grouped together into key themes. Analysis delivered nine categories according systematic ordering of the themes (different views) that emerged from the responses. ${ }^{22}$ Within these categories conflicting views were found. For the purposes of this paper further analyses were aimed at identifying the themes related to the conflicts mentioned by participants. Based on these analyses three topics were identified: (1) parental duties, (2) the woman's needs and wishes and (3) the woman's ethical principles.

\section{RESULTS}

The results identify the conflicting aspects reported. 'Participants' indicates the whole study group. Where statements are quoted, the woman's code number, group, and whether she had decided to accept (acceptor) or decline (decliner) the test are given. The findings from the two intervention groups are presented together. From the RCT no differences were found in views between participants in the NTM and MST groups. ${ }^{12}$

\section{Parental duties}

\section{Towards the unborn}

Participants agreed that parents have a duty to look for the health and wellbeing of their unborn child. This duty was not linked to the use of prenatal testing, nor to the prevention of disability. Participants limited their responsibility to the avoidance of actions that might have a negative influence on the health of the fetus, such as smoking or drinking alcohol. Reasons for not including testing as a parental obligation included that the screening does not give sufficient information for further decisions and the awareness that testing does not guarantee a completely healthy life for the child.

\section{"Actually, everybody wants a healthy child. But there are so many things that can go wrong! You never have a guarantee that everything is good also when you do all those tests." (060900-79; NTM, decliner)}

Acceptors and decliners differed in their view about the significance of testing within their duties towards their unborn child. Although none of the acceptors aimed to avoid a child with Down syndrome, they used the screening to guarantee the health of the fetus. At the same time, acceptors reported their unwillingness to take further decisions because of the difficulty in assessing which level of suffering should be prevented in the interest of the child.

\begin{abstract}
"How can you find out what is good for the child? To what degree does such a child realise that he has a disability? I find this quite difficult. My brother is deaf. For others it is awful, but he does not know it can be different, he has always been deaf. He has done very well in his life; he has a family, two healthy children. You could have decided that he should not be born, while he is very happy". (060900-68; MST, acceptor)
\end{abstract}

Decliners considered avoiding unnecessary risks as the best action in the interest of the child. Important reasons given were the ambiguity of the screening results and the risks of invasive testing. At the same time, decliners questioned whether they had to use the test in the interest of their future child.

"I think that disabled children have many qualities that can be stimulated. On the other hand, which future does such a child have? Well, this is quite problematic. The child may suffer, so are you not selfish if you allow him to be born? That is a very difficult issue".(K07811-22; MST, decliner)

\section{Towards their other children}

Participants reported the effect of a disabled child on their family as important in their decision about screening. Both acceptors and decliners indicated that they would make another choice if their personal and familiar circumstances were different.

In the case of a disability that might be compatible with a reasonably good life, participants questioned to what extent family interests should weigh against the life of the unborn. Disability was not always entirely considered without value. Participants mentioned that a disabled child might have a positive effect on the family. In spite of this opinion, they concerned about the burdens that their family could face when a disabled child is born.

\footnotetext{
"I think you can learn a great deal from these situations. That in life sometimes things happen through which you become more aware that little things mean a lot. But I feel some pressure, because of the impact on my family. This is quite difficult." (K18811-89; MST, acceptor)
}

A difference between acceptors and decliners was found in the extent to which they thought that raising a disabled child would impede them in fulfilling their parental responsibilities 
towards their other children. Acceptors feared that they would be unable to give enough attention to their family because of the extra care a disabled child would require.

\footnotetext{
"You never know how your life will be. But this is one of the things you can know beforehand. I am very happy with my life; I have a daughter who is 1 year old. It is very important for me that my children are happy and this would be very difficult with a child with Down syndrome because it will need extra care."(K03400-7; NTM, acceptor)
}

For decliners, a reason against testing was their perceived capacity to deal with a disabled child and the care for other children. At the same time, they were aware of the extra care that a child with Down syndrome needs and questioned whether declining the test would not be against their responsibilities towards their family.

For me this child is number two. A child with Down syndrome should require extra care. Perhaps that will be a reason for me to terminate my pregnancy because my child would get less attention. A child with Down syndrome would be prejudicial for my family." (K07811-52; NTM, decliner)"

\section{Women's needs and wishes}

Participants made their decision to reduce anxiety during pregnancy. All of them said they were satisfied with their final choice, even when they reported that it was not an easy one.

Acceptors chose testing moved by a wish for more knowledge to avoid the anxiety of wondering if their baby was healthy and to confirm that everything was good. On the other hand, they reported reluctance to make further decisions. They postponed thinking about further options until the screening results were known.

\begin{abstract}
"I'm sure that I want to take the test. What will I do with the result? Well I will see. That's the problem. I do not want to think. I feel that I want to keep the baby but I also think that I will terminate.I have doubts about what is the best choice." (K38311-76; NTM, acceptor)
\end{abstract}

Decliners chose to avoid the uncertainty and anxiety that might come with the screening. The fear of a miscarriage due to invasive procedures was reported as not weighing against their desire for reassurance about the health of the fetus. At the same time, decliners welcomed information. They admitted they would consider testing if the screening gave a sure diagnostic.

\footnotetext{
"It is a chance approximation and this implies you have actually to perform an extra test. And that test is risk. I think that if I did not need to do that extra test I would take the screening." (075400-9; NTS, decliner)
}

\section{Women's ethical principles}

Participants shared the view that parents ought to accept their children unconditionally. They considered an exception to this rule is if the child would be severely disabled with a life full of suffering. In this case, participants agreed that parents have a duty to decide about the birth of the child based upon the child's best interests. Even so, termination was reported to be morally problematic because it clashes with the right to life of the child. Participants expressed doubt about the reasons that would make termination of pregnancy morally acceptable. They voiced worries that only perfect children may be born in the future.
"I find abortion acceptable when you honestly do it in the interest of the child because you cannot care for it and then it would be unhappy. But there are so many reasons that I find egoistic. I wonder whether we are like sitting on the chair of God, in case He exists, that we want to decide about those things. I think that we are going too far in this feasible world, that we want everything to be perfect." (K18811-67; NTM, decliner)

Termination of pregnancy in case of disabilities that may be compatible with a good life was reported as egoistic. Down syndrome was not assumed to be the kind of suffering that parents ought to prevent. Nevertheless, participants approved termination when parents cannot cope with such a child, for the child would not have the care and love that is needed for a good life.

"If the parents are convinced they cannot care for the child and they allow it to be born, that child would not be happy. Neither would the parents. I fear that the child would be neglected. Certainly, I disapprove of the parents, but on the other hand I also think that it is not good for the child to be born with parents who do not want it." (K03711-01; MST, decliner).

One of the main reasons decliners gave for not testing was that termination would be morally wrong in their personal circumstances. At the same time, decliners reported their difficulty to know in what cases termination would be a good option looking to the interest of the child.

"Actually, you think in terms of quality of life. Is it severely disabled or is it a child who should have a good life, also if it has limitations? I find it very difficult to know what the best decision is. Neither do I know what the boundaries are." (K18811-77; MST, decliner)

\section{DISCUSSION}

In this paper we explored the effect of an active offer of a prenatal screening test in a context where testing is not normal part of prenatal care. In contrast to studies that maintain that information facilitates women in making well-considered decisions, participants described the choice as difficult to make because of the implications of the test results not only for the future child, but also for their family and ultimately for themselves. Although they were positive about their choice, participants mentioned they found themselves caught between a desire for information and reassurance about the health of the fetus and their fear of making difficult decisions about their unborn child. They were concerned as to what degree family and personal wellbeing may be weighed against the right to life of the fetus. The main question at this point is whether this difficulty can be defined as a genuine ethical dilemma.

A moral dilemma occurs when an agent has valid moral reasons to support two or more exclusive actions, at least one of which they are required to do. These reasons involve moral principles that are equally strong and values that are equally central to the life of the agent. Participants claimed their right to freely decide whether they want to use testing according to their assessment of the usefulness of the test in their individual and family circumstances. Closely related to this is the physical and emotional burden they expected from a disabled child on their family life. Down syndrome in itself was reported as a morally insufficient reason for termination. Nevertheless, participants judged termination as morally acceptable when parents cannot cope with the effect of such a child on their personal and family life. At the same time, participants voiced 
ethical concerns about selection of "perfect" children and questioned what would constitute a sufficiently serious disability to justify termination. All of them were reluctant to consider having a termination themselves. These results suggest that women's preferences about testing often deviate from their ethical values.

Based on these results, we believe that women to whom testing is offered are confronted with a decision about what interests, preferences or needs would be given priority and not about two or more ethical principles they are compelled to follow. Therefore, we cannot define it as a genuine moral dilemma. Our results indicate that the possibility of testing generates a wish for extra information. At the same time, women fear the consequences of testing. Participants decided by balancing the interest of the fetus against their individual wishes and the family needs to find the option that was most in line with their values. The conflict that women reported could be interpreted as the difficulty of assessing the usefulness of the screening to their personal situation. Although participants embraced their decision, they also reported that they would decide differently in other circumstances.

Our findings also suggest the existence of a gap between ethical decisions in practice and those based on ethical theory regarding the possibility of moral dilemmas. Anderson claims that moral dilemmas are only possible within the Kantian approach of ethics in which personal and moral matters are separated and in which moral principles are universal expressions of our moral duties. ${ }^{28}$ This entails that the decision about what is right and what is wrong is reduced to the rational application of ethical principles and norms. According to this approach, conflicts between principles must be rationally resolved by consulting a higher-level principle. When different ethical principles are both equally relevant to apply, an agent is caught in a situation in which there is no way to determine which choice is morally right for the particular situation. ${ }^{29-31}$ In this way, ethical decisions are reduced to technical decisions undermining the importance of the individual desires, preferences, circumstances and the possible consequences, in the decision-making.

However, as our results show, a rational and purely abstract analysis of the factors involved without taking into consideration the concrete persons who are embodied or implicated in the decision regarding testing is unlikely to capture the emotional and circumstantial concerns in which decisions are made. Furthermore, rational analyses of normative decisions often fail to take into consideration agent's values and desires, which are difficult to quantify. ${ }^{32} 33$

This suggests a clear need for a new ethical framework of thinking in reproductive decisions. The neo-Aristotelian ethical approach might be a promising alternative for identifying the nature of the conflicts that women reported when deciding about testing. This framework of ethical thinking assumes that the morality of an action varies with the circumstances of each particular occasion. Within this approach, an action is morally right only if it is what a virtuous person would do in the same circumstances. The central question when deciding about testing is not "is the action against any ethical principle?" or "does it harm anyone?" but rather "what would a good parent do in these circumstances?". Two fundamental characteristics of good parenthood are accepting children as they are and safeguarding the children's wellbeing and happiness. Parenthood is at the same time a self-directed project. In deciding about testing, women are compelled to determine the effect of knowledge about the fetus in their acceptance and pursuit of the wellbeing of their children and in their own interest. The individual concept of a good life and the consequences of their choice in the short and long term play a central role in defining their decision.

This study was developed in a context where there was no routine screening on offer. Despite this, our findings may also have implications for countries where testing is a standard procedure. As Suter suggests, the offer of testing might be regarded as self-evident and women would be likely to participate automatically without considering its ethical implications. ${ }^{34}$ Moreover, women might believe that they are morally compelled to use testing in the interest of their child and family.

In the light of these results, we believe that addressing the nature of the conflict women experience when deciding about testing needs to be carefully analysed before new screening tests are offered to a general, low-risk population. We propose that routine offering of prenatal screening and testing is ethically justified when the offer is accompanied by broad-based counselling. As counselling aims to assist women to choose the course of action most appropriate to them in view of their goals and according to the ethical values they hold, identifying this conflict should help caregivers to discern whether women make their decisions under pressure from needs, wishes and additional duties that might be triggered by the test offer and therefore not in the line with their ethical values.

To help women to assess the meaning of testing within their parental duties, counselling should include discussion of the effect of the woman's wishes and preferences regarding testing, her familiar context-bounded needs and her ethical values. Caregivers should ensure that women understand the advantages and disadvantages of testing and the scenarios they might face in case of a bad test result. Furthermore, all options, including that of not testing should be presented. Some practical points that may be discussed are: the women's thoughts about life with a child with Down syndrome; what they want to do with the information once they have $t$ it (that is, whether they want to take further tests and whether termination would be an option) and whether they would prefer to be confronted with a disabled child at the time of birth or to prepare themselves and their family beforehand.

Competing interests: None declared.

Provenance and peer review: Not commissioned; externally peer reviewed.

\section{REFERENCES}

1. Health Council of the Netherlands: Committee on the Population Screening Act. 1996. Population screening act: the assessment of permit applications, 1996/ 09WBO. The Hague: Health Council of The Netherlands.

2. Health Council of the Netherlands. Prenatal screening: Down's syndrome, neural tube defects, routine-ultrasonography. The Hague, Health Council of the Netherlands 2001/11.

3. Kristol E. Picture perfect: the politics of prenatal testing. First Things 1993;32:17-24

4. Brookes A. Women's voices: prenatal diagnosis and care for the disabled. Health Care Anal 2001;:9:133-50.

5. O'Conner AM, Jacobsen MJ, Stacey D. An evidence based approach to managing women's decision conflict. J Obstet Gynecol Neonatal Nurs 2002;31:570-81.

6. Getz L, Kirkengen AL. Ultrasound screening in pregnancy: advancing technology, soft markers, for fetal chromosomal aberrations and unacknowledged ethical dilemmas. Soc Sci Med 2003;56:2045-57.

7. Marteau TM, Dormandy E, Michie S. A measure of informed choice. Health Expec 2001:4:99-108.

8. Bennett MJ, Gau GS, Gau DW. Women's attitudes to screening for neural-tube defects. Br J Obstet Gynaecol 1980;87:370-1.

9. Berne-Fromell K, Josefson G, Kjessler B. Who declines from antenatal serum alphafetoprotein screening-and why? Acta Obstet Gynecol Scand 1984;63:687-91.

10. Markens S, Browner CH, Press N. Because of the risks: how US pregnant women account for refusing prenatal screening. Soc Sci Med 1999;49:359-69.

11. Michie S, Smith D, Marteu TM. Prenatal test: how are women deciding? Prenat Diagn 1999:19:7438.

12. Van der Berg $\mathbf{M}$, Timmermans DR, Kleinveld JH, et al. Accepting or declining the offer of prenatal screening for congenital defects: test uptake and women's reasons Prenat Diag 2005;25(1):84-90. 
13. Jørgensen FS. Declining an alpha protein test in pregnancy, why and who? Acta Obstet Gynecol Scand 1995;74:3-11.

14. Liamputtong $\mathbf{P}$, Halliday $J \mathrm{~L}$, Warren $\mathrm{R}$, et al. Why do women decline prenatal screening and diagnosis? Australian women's perspective. Women Health 2003;37:89-108.

15. Sher C, Romano-Zelekha 0, Green MS, et al. Factors affecting performance of prenatal genetic testing by Israeli Jewish women. Am J Med Genet A 2003;120A:418-22.

16. Andrews LB. Prenatal screening and the culture of motherhood. Hastings Law J 1996;47:967-1006

17. Marteau TM, Dormandy E. Facilitating informed choice in prenatal testing: How well are we doing? Am J Med Genet 2001;106:185-90.

18. Press N, Browner CH. Why women say yes to prenatal diagnosis. Soc Sci Med 1997:45:979-89.

19. Hildt E. Autonomy and freedom of choice in prenatal genetic diagnosis. Med Health Care Philo 2002;5:65-71.

20. Downing C. Negotiating responsibility: case studies of reproductive decision-making and prenatal genetic testing in families facing Huntingtondisease. J Genet Couns 2005;14:219-34.

21. Kleinveld JH, Timmermans DR, de Smit DJ, et al. Does prenatal screening influence anxiety levels of pregnant women? A longitudinal randomised controlled trial. Prenat Diag 2006;26:354-61.
22. Garcia E, Timmermans DR, van Leeuwen E. Impact of ethical beliefs on decisions about prenatal screening tests: searching for justification. Soc Sci Med 2008;66:753-64.

23. Garcia E, Timmermans DR, van Leeuwen E. Rethinking autonomy in the context of prenatal screening decision-making. Prenat Diagn 2008;28:115-20.

24. Fletcher J. Ethical issues in genetic screening and antenatal diagnosis. Clin Obstet Gynecol 1981;24:1151-68.

25. Hubbard R. Eugenics: new tools, old ideas. Women Health 1987;13:225-235.

26. Post SG. Huntington's disease: prenatal screening for late onset disease. J Med Ethics 1992;18:757-8.

27. Ahmed S, Green JM, Hewison J. Attitudes towards prenatal diagnosis and termination of pregnancy for thalassemia in pregnant Pakistani women in the North of England. Prenat Diagn 2006;26:248-57.

28. Anderson LV. Moral dilemmas, deliberation, and choice. J Philos 1985;82:139-62

29. Marcus RB. Moral dilemmas and consistency. J Philos 1980;77:121-36.

30. McConnell T. More on moral dilemmas. J Philos 1986;83:345-51.

31. Macintyre A. Moral dilemmas. Philos Phen Res 1990;50(suppl):367-82.

32. Ubel PA, Lowenstein $\mathrm{G}$. The role of decision analysis in informed consent: choosing between intuition and systematicy. Soc Scien Med 1997;44:647-57.

33. Kahneman D, Tversky A. Prospect theory: an analysis of decision under risk. Econometrica 1979:47:262-91.

34. Suter SM. The Routinization of prenatal testing. Am J Law Med 2002;28:233-70. 